\title{
Discounting disentangled
}

\author{
Moritz Drupp, Mark Freeman, \\ Ben Groom and Frikk Nesje
}

November 2015

Centre for Climate Change Economics and Policy

Working Paper No. 195

Grantham Research Institute on Climate Change and the Environment

Working Paper No. 172 
The Centre for Climate Change Economics and Policy (CCCEP) was established by the University of Leeds and the London School of Economics and Political Science in 2008 to advance public and private action on climate change through innovative, rigorous research. The Centre is funded by the UK Economic and Social Research Council. Its second phase started in 2013 and there are five integrated research themes:

1. Understanding green growth and climate-compatible development

2. Advancing climate finance and investment

3. Evaluating the performance of climate policies

4. Managing climate risks and uncertainties and strengthening climate services

5. Enabling rapid transitions in mitigation and adaptation

More information about the Centre for Climate Change Economics and Policy can be found at: http://www.cccep.ac.uk.

The Grantham Research Institute on Climate Change and the Environment was established by the London School of Economics and Political Science in 2008 to bring together international expertise on economics, finance, geography, the environment, international development and political economy to create a worldleading centre for policy-relevant research and training. The Institute is funded by the Grantham Foundation for the Protection of the Environment and the Global Green Growth Institute. It has nine research programmes:

1. Adaptation and development

2. Carbon trading and finance

3. Ecosystems, resources and the natural environment

4. Energy, technology and trade

5. Future generations and social justice

6. Growth and the economy

7. International environmental negotiations

8. Modelling and decision making

9. Private sector adaptation, risk and insurance

More information about the Grantham Research Institute on Climate Change and the Environment can be found at: http://www.Ise.ac.uk/grantham.

This working paper is intended to stimulate discussion within the research community and among users of research, and its content may have been submitted for publication in academic journals. It has been reviewed by at least one internal referee before publication. The views expressed in this paper represent those of the author(s) and do not necessarily represent those of the host institutions or funders. 


\title{
Discounting Disentangled
}

\author{
Moritz A. Drupp ${ }^{1}$, Mark C. Freeman ${ }^{2}$, \\ Ben Groom ${ }^{3}$ and Frikk Nesje ${ }^{4 *}$
}

As the most important driver of long-term project evaluation, from climate change policy to infrastructure investments, the social discount rate (SDR) has been subject to heated debate among economists. To uncover the extent and sources of disagreement, we report the results of a survey of over 200 experts that disentangles the long-term SDR into its component parts: the pure rate of time preference, the wealth effect, and the real risk-free interest rate. The mean recommended SDR is 2.27 percent, with a range from 0 to 10 percent. Despite disagreement on point values, more than three-quarters of experts are comfortable with the median SDR of 2 percent, and over 90 percent find an SDR in the range of 1 to 3 percent acceptable. Our disentangled data reveal that only a minority of responses are consistent with the Ramsey Rule, the theoretical framework dominating discounting policy. Instead, experts recommend that governmental discounting guidance should be updated to deal with uncertainty, relative prices, and alternative ethical approaches.

Keywords: Social discount rate, project appraisal, expert opinions, disagreement. JEL codes: H43, D61, Q58.

\footnotetext{
${ }^{* 1}$ Department of Economics, University of Kiel, Germany; mail: Drupp@economics.unikiel.de ${ }^{2}$ School of Business and Economics, Loughborough University, United Kingdom; mail: M.C.Freeman@lboro.ac.uk. ${ }^{3}$ Department of Geography and Environment, London School of Economics, United Kingdom; mail: b.groom@lse.ac.uk. ${ }^{4}$ Department of Economics and ESOP, University of Oslo, Norway; mail: frikk.nesje@econ.uio.no. We would like to express our deepest gratitude to our many survey respondents for their time and thoughts. We further thank Julius Andersson, Geir Asheim, Stefan Baumgärtner, Wolfgang Buchholz, Simon Dietz, Bård Harstad, Cameron Hepburn, Svenn Jensen, Antony Millner, Kian Mintz-Woo, Paolo Piacquadio, Martin Quaas, Thomas Sterner, Gernot Wagner and Marty Weitzman as well as seminar audiences at Bergen, Berlin, Camp Reinsehlen, EAERE 2015, Edinburgh, EEA 2015, EnvEcon 2015, Geneva, Gothenburg, Hamburg, Kiel, Oslo, Ulvön 2015 and ZEW for helpful discussions. We thank the LSE Research Seed Fund for financial support and Natalia Grinberg for research assistance. Drupp is grateful for financial support from the German National Academic Foundation, the DAAD, and the BMBF under grant 01LA1104C. Author for correspondence: Ben Groom.
} 


\section{Introduction}

We report the results of a survey of experts on the appropriate long-term real social discount rate (SDR). The sample contains over 200 academics who are defined as experts on social discounting by virtue of their publications. We elicit responses, both quantitative and qualitative, on each expert's approach to intergenerational discounting. A key innovation of our survey is that we elicit the recommended values for the individual components of the Ramsey Rule. Together with the recommended point value of the SDR and its acceptable range, the responses allow us to disentangle the sources of disagreement on the SDR. Our findings lead us to the conclusion that current policy guidance concerning social discounting and the evaluation of longterm public projects requires significant revision.

The opinions of experts who are "genuine specialists" play an important role in public policy. One need only look at the Stern Review and the numerous expert panels held in recent years to see that social discounting is no exception. Governments listen to what experts say on this matter. ${ }^{1}$ Yet, to date, there is no detailed survey of expert opinion on discounting. This is a serious omission since discounting the distant future has been described as "one of the most critical problems in all of economics" (Weitzman 2001: 260). Views on discounting differ substantially and over the past decades economists have found themselves either stumbling around in the "dark jungles of the second best" in pursuit of an answer or accused of "stoking the dying embers of the British Empire" if they claim to find one (Baumol 1968: 789; Nordhaus 2007: 691). Despite this, we have little understanding of the source or extent of this disagreement. In this context, the Ramsey Rule has been a constant presence as the workhorse representation of the SDR, serving as a "useful conceptual framework for examining intergenerational discounting issues" (Arrow et al. 2012: 3). Policy guidelines on cost-benefit analysis across the world are testament to this view (HMT 2003; IPCC 2014; Lebegue 2005). However, the exact role that the Ramsey Rule should play is controversial, as are the appropriate values for its individual parameters (Dasgupta 2008; Nordhaus 2007; Stern 2007; Weitzman 2007).

Disagreement typically stems from the three different representations of the rule, and the normative-positive content of its parameters (Arrow et al., 1996). Originally,

\footnotetext{
${ }^{1}$ Since the Stern Review, expert advice on social discounting has been sought from specialists in the field by the United States Environmental Protection Agency (US EPA), and the Norwegian, French, UK and Dutch governments.
} 
it was presented as an optimality condition for the savings decisions of a representative agent (Ramsey 1928). On the optimal path the marginal productivity of capital, $r$, equals the Social Rate of Time Preference (SRTP), defined as the right hand side of Equation 1:2

$$
r=S D R=\delta+\eta g
$$

The SRTP is composed of the rate of pure time preference or utility discount rate $(\delta)$, and the interaction of the expected real growth rate of per-capita consumption $(g)$ and the elasticity of marginal utility of consumption $(\eta)$. Another interpretation of the Ramsey Rule associates the SDR solely with the SRTP: $S D R=\delta+\eta g$. This approach focuses on the trajectory of consumption while ignoring that of the capital stock on the production side. It is typically considered to be the normative or prescriptive approach to determining the SDR, and is the interpretation followed by Her Majesty's Treasury in the United Kingdom (HMT 2003), for instance. Finally, there is the opportunity cost of capital approach: $S D R=r$. Here the focus is on the trajectory of the capital stock, while that of consumption is ignored. This approach is informed by anchoring the SDR in an observable rate of return in the market place, such as the yield on government bonds. This is the positive or descriptive approach followed by the US EPA (2010), among others.

Without explicitly referencing the Ramsey Rule, our survey seeks the opinions of experts not only on the SDR itself, but also on the values of its components and determinants $(r, \delta, \eta$, and $g)$. This allows us to disentangle expert disagreement on the SDR into some of its fundamental constituent parts.

The responses make for interesting reading. The mean (median) recommended SDR of our experts is 2.27 percent (2 percent). This is substantially lower than the mean (median) values 3.96 percent (3 percent) reported in the seminal survey by Weitzman (2001), yet the modal value of 2 percent is the same. We also find that there remains substantial disagreement between experts over this value, with individual recommendations ranging between 0 and 10 percent. Despite this, 92 percent of experts report that they would be comfortable with a SDR somewhere in the interval of 1 percent to 3 percent, and over three-quarters find a SDR value of 2 percent acceptable.

\footnotetext{
${ }^{2}$ The First Welfare Theorem applies in the equivalent perfectly competitive economy, so the optimality condition in Equation 1 can be thought of as an equilibrium condition.
} 
Looking at the empirical distributions of the individual determinants of the discount rate, we find that expert opinion is particularly varied on the appropriate rate of pure time preference. The modal value is zero, in line with many prominent opinions, including Ramsey (1928) himself. But with a mean (median) of 1.1 percent (0.5 percent), the results do not confirm the IPCC's (2014: 229) conclusion that "a broad consensus for a zero or near-zero pure rate of time preference" exists. Also, while we find that experts, on average, recommend placing greater weight on normative than positive issues when determining the SDR, most believe that the SDR should be informed by both.

An unambiguous result of our survey is that the prominence of the simple Ramsey Rule in public policy needs to be revisited. When we use the Ramsey Rule to impute an individual SDR for each expert, we find that there are wide discrepancies between this value and their recommended SDR. Both the average SRTP and the forecasted risk-free interest rate are higher than the average recommended SDR. The rich body of qualitative responses provided by our experts further stresses the need for policy on long-term public decision-making to depart from the confines of the simple Ramsey Rule. Accounting for a more comprehensive set of technical issues, such as uncertainty and relative prices of non-marketed goods, was one set of recommended departures. Ensuring that decision-making on long-term public policies is participatory and takes a more procedural approach, was another. A third set of recommendations stressed the importance of different societal criteria which embody broader notions of intergenerational equity and sustainability.

There are good arguments for a more "democratic" approach to informing governmental guidance on social discounting (Dasgupta 2008: 158). Yet, because the questions raised by long-term discounting are highly complex, there are also strong reasons for so-called "genuine specialists" (Pindyck 2015; Sunstein 2014: 550) to play an active role. Precisely because discounting policy is so often influenced by experts who are specialists in the field, it is imperative to obtain a more complete picture of the range of opinions they hold. By presenting the responses of a large number of experts on the determinants of the long-term SDR, this paper contributes to the ongoing academic debate over improving conceptual approaches to intergenerational decision-making. It also provides detailed information for the discounting policy revisions taking place in several countries. 


\section{Survey Design and Expert Selection 2.1. The Survey Questions}

The survey asked respondents about the SDR and its determinants within the setting of the Ramsey Rule. The questionnaire began with the following contextual preamble:

Imagine that you are asked for advice by an international governmental organization that needs to determine the appropriate real social discount rate for calculating the present value of certainty-equivalent cash flows of public projects with intergenerational consequences.

For its calculations, the organization needs single values for the components of the real social discount rate. While this does not capture all of the important complexities of social discounting, it does reflect most existing policy guidance on the matter. Your answers will therefore help to improve the current state of decision-making for public investments.

Specifically, you are asked to provide your recommendations on the single number, global average and long-term (>100 years) values of the following determinants of the social discount rate:

This was followed by seven brief quantitative questions and an optional comments section for qualitative responses. The full survey text is presented in the Appendix. ${ }^{3}$

Questions 1-3 elicited responses on the three individual parameter values that underlie the Ramsey Rule's SRTP approach; $\delta, \eta$ and $g$. Question 4 asked for a forecast of the long-term global average real interest rate, $r$. Question 6 asked for the point-value of the SDR that should be recommended for evaluating the certaintyequivalent cash flows of a generic global public project with intergenerational consequences. ${ }^{4}$ Having a separate question on the SDR meant that respondents could deviate from both the real risk-free interest rate and the SRTP if they so wished,

\footnotetext{
${ }^{3}$ We had previously piloted different potential versions of the survey with selected discounting experts, economists from different fields, and students to find the best trade-off between completeness and parsimony.

${ }^{4}$ For reasons of parsimony, the survey was not designed to elicit opinions on the treatment of uncertain future benefits in intergenerational cost-benefit analysis.
} 
and allowed more complex issues in social discounting to be manifested in their recommended SDR. The survey did not refer to the Ramsey Rule explicitly to avoid providing a cue to respondents that they should conform to it. As a result, the survey did not include a direct mechanism to extract the rationales for deviating from the Ramsey Rule. However, the open comments section, Question 8, allowed for feedback on the survey, where respondents could, and often did, point towards various deviations from the Ramsey Rule.

Question 5 elicited information about each respondent's approach to discounting by asking for the relative weight that the governmental body should place on normative versus positive approaches to determining the SDR. Responses were measured on a sliding scale from 0 to 100 percent. This question intended not only to highlight potential heterogeneity in responses, but also to explore the disagreement in rationales that has been evident at least since Arrow et al. (1996): whether normative issues, involving intergenerational ethics and justice, or positive issues, involving forecasted future returns to financial assets, or a mixture of both should determine the SDR. Importantly, the sliding scale admits many interpretations of normative and positive other than those associated with the Ramsey Rule. For instance, responses could reflect the relative weight that respondents place on different consequentialist or deontological ethical frameworks. In Question 7 we asked for the minimum and maximum values of the SDR that respondents would be comfortable with recommending, in order to elicit an 'agreeable range'.

\subsection{Expert Selection and Survey Dissemination}

Because our survey aimed at disentangling the determinants of the long-term SDR, we restricted our sample to scholars who have been involved with these complex issues and hence can be considered genuine specialists. For the purposes of this paper, an individual is deemed to be an "expert" if he or she is a (co-)author of at least one pertinent publication in the field of (social) discounting in a leading economics journal. A journal was classified as "leading" if, according to the ranking of 600 economics journals by Combes and Linnenmer (2010, Table 15), it is rated A or higher, together with the highly relevant Review of Environmental Economics and Policy. This amounts to 103 peer-reviewed journals. A publication is deemed to be "pertinent" if it was published between January 2000 and March 2014 and, according to the Google Scholar engine, included at least one of the terms 'social discounting', 
'social discount rate' or 'social discount factor'. We further performed an EconLit abstract-based search for the broader term 'discount rate' within the same journals. Correcting for scholars with multiple publications, and also discarding papers that did not pass a weak relevancy test (see Supplementary material A), our sample of potential experts includes 627 scholars.

There are some limitations to this selection strategy. First, by restricting the search to publications since the year 2000 to only capture scholars active in the current debate on social discounting, we potentially miss some relevant earlier contributors. Second, by selecting experts based on their publications, we necessarily include co-authors of relevant papers who are not themselves experts on discounting. Third, due to the rather generous weak relevancy test, we include a number of scholars who might not regard themselves as true experts on the issue. Fourth, we do not pick up relevant publications in the field that have used other terms to discuss discounting. Finally, we miss potentially relevant articles in lower-ranked journals. This may introduce a geographical bias into our sample by under-representing those from developing nations.

Despite these possible short-comings, the definition of expert that we deploy here is close to the one frequently used by policy makers, both in general policy contexts and in relation to social discounting.

Starting in May 2014, we sent out a link to the online survey (implemented in SurveyMonkey) via e-mail to all potential experts, and used three general rounds of reminders, each time slightly varying the subject line and motivation for answering the survey (Supplementary material B provides the initial e-mail text). In later rounds, we offered the option of completing the survey in a Word document or the e-mail itself to increase flexibility.

\section{Survey Results}

Table 1 provides summary statistics for each quantitative question in the survey as well as the imputed SRTP for each expert.

By November 2014 we had received quantitative and qualitative responses from 197 experts, including 12 who solely provided qualitative feedback containing important insights. We also received replies from 27 scholars explaining why they did not answer the survey and whose answer did not warrant inclusion as a qualitative 


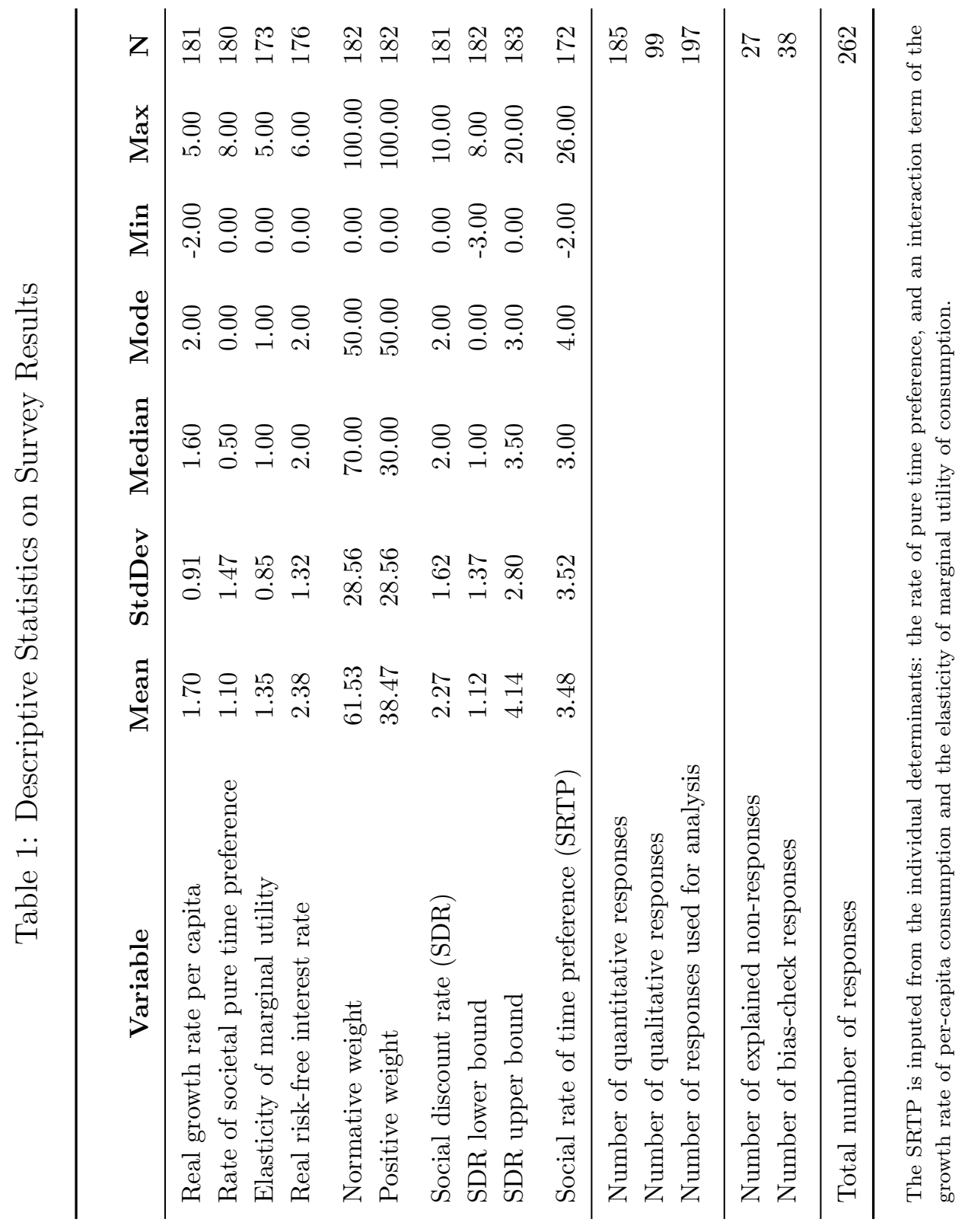


response. The most common reason for such non-response was self-reported insufficient expertise, but it also included simply not having enough time or being unable to respond due to reasons of central bank confidentiality. Responses were also obtained after the survey closed from 38 previous non-respondents. This group is used to check for non-response bias.

Overall, we elicited 262 responses out of a pool of 627 potential experts. The response rate is 30 percent if we only consider the 185 quantitative responses. If we include all responses, the rate rises to 42 percent. Each is in line with comparable online surveys with economists (Necker 2014). Besides this, the sampling strategy was successful in obtaining responses from "blue ribbon" academic leaders on social discounting including 12 of the 13 experts of the Arrow et al. (2012) panel who advised the US EPA on this matter.

\subsection{Quantitative Responses}

\subsubsection{Recommended Long-Term Social Discount Rate}

In recent years, prominent experts such as Gollier (2012), Nordhaus (2008), Stern (2007) and Weitzman (2007) have proposed very different SDRs. Figure 1 (a) illustrates the extent of disagreement on the SDR for discounting real certaintyequivalent cash flows of a global public project with intergenerational consequences. The lowest recommendation is 0 and the highest 10 percent. However, the vast majority of experts provide point recommendations in the range of 0 to 4 percent, while the interval of 1 to 3 percent contains the point SDR recommendations of 68 percent of experts. The mean (median) value of the recommended SDR are 2.27 percent (2 percent), which are much lower than the corresponding values from Weitzman's (2001) survey of economists of 3.96 percent (3 percent). Yet the most common single value recommended in these two different surveys is 2 percent. These results deviate significantly from the discount rates recommended in important recent guidelines, including the IPCC Fifth Assessment Report (IPCC 2014: 230). ${ }^{5}$ 


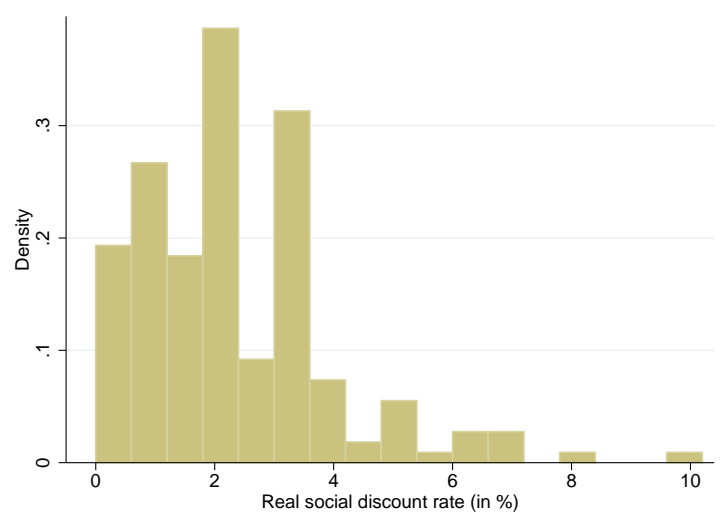

(a)

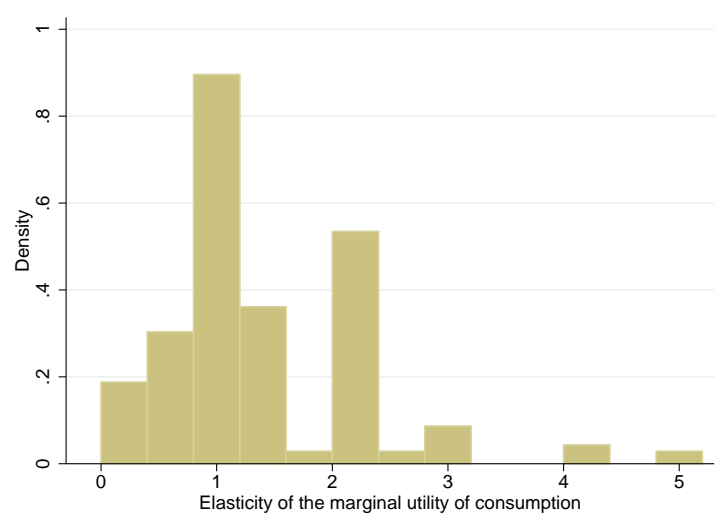

(c)

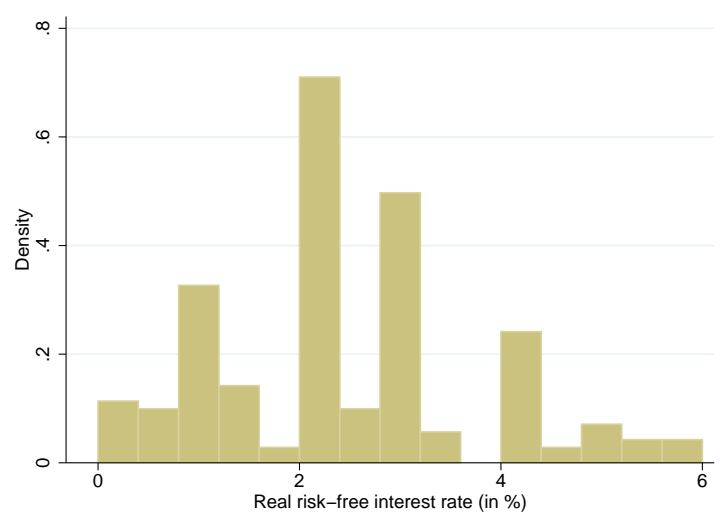

(e)

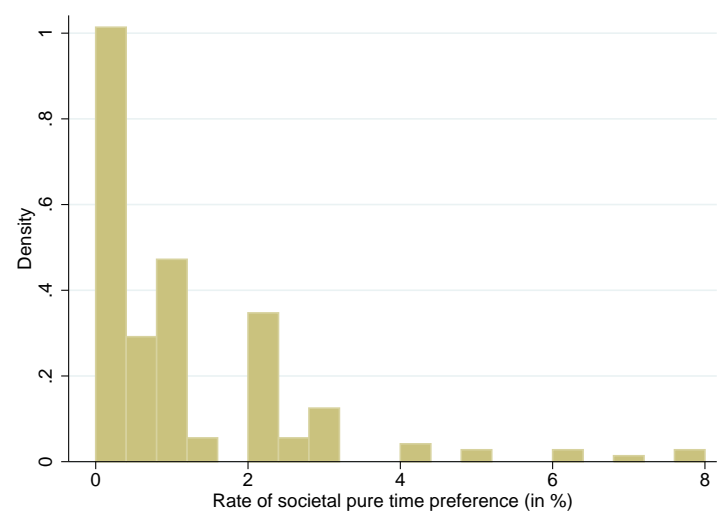

(b)

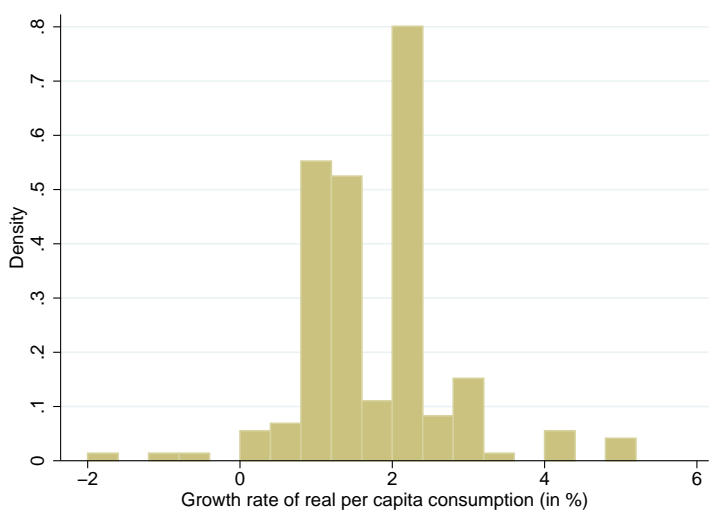

(d)

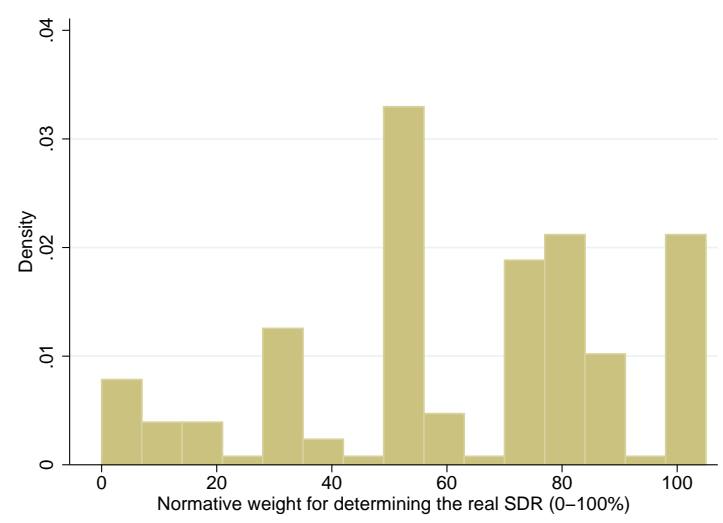

(f)

Figure 1: This figure provides histograms of expert recommendations and forecasts on determinants of discounting parameters. Figure (a) shows the real long-term SDR (in percent), (b) rate of societal pure time preference (in percent), (c) elasticity of marginal utility of consumption, (d) real growth rate of per capita consumption (in percent), (e) real risk-free interest rate (in percent), and (f) the normative weight for determining the SDR (in percent). 


\subsubsection{Rate of Societal Pure Time Preference}

Positions on the rate of societal pure time preference, $\delta$, have historically been the subject of intense disagreement. Luminaries of economics, such as Pigou, Ramsey and Harrod, believed that the well-being of each generation ought to be weighted equally, and so pure time preference should be zero. This view stems from their classical impartial Utilitarian philosophy. Disagreement surfaced again more recently with the publication of the Stern Review (Stern 2007), which took the same classical Utilitarian stance. Many alternative arguments exist for the use of a positive rate of societal pure time preference (e.g. Arrow 1999; Koopmans 1960; Nordhaus 2007). Figure 1 (b) shows substantial disagreement among experts on their chosen value for this parameter. As the modal value, a rate of zero is a focal point, and, if we include those responses that lie in the range of 0 to 0.1 percent, 38 percent take what might be called the Ramsey-Stern view. Yet, the distribution of responses is substantially right skewed with a median of 0.50 percent, a mean of 1.10 percent and a maximum recommendation of 8 percent. Based on these results, we cannot confirm the IPCC's (2014: 229) conclusion that "a broad consensus for a zero or near-zero pure rate of time preference" exists among experts.

\subsubsection{Elasticity of the Marginal Utility of Consumption}

Settling on a value of the elasticity of the marginal utility of consumption, $\eta$, is an intricate affair. The reason is that it might capture vastly different concepts and thus lend itself to different interpretations. These are not only divided along the lines of normative (e.g., issues of distribution) and positive (e.g., preferences for consumption smoothing) determinants, but might also capture the inverse of the elasticity of intertemporal substitution or societal preferences for the aversion of consumption inequalities across space, time and also states of nature. All these rationales could have been used by different experts to inform their response, although the survey setting might reasonably have led respondents to primarily consider interpretations relating to an intertemporal context. Previous discussions in the literature point towards a range of 0.5 to 4 (Cowell and Gardiner 1999; Dasgupta 2008). The re-

\footnotetext{
${ }^{5}$ The results are closer to recent findings by Giglio et al. (2015) for long-term discount rates estimated from the housing market in Singapore and the UK, which imply risk-free discount rates of around 1 percent for 100-year claims on leaseholds.
} 
sulting expert recommendations for elasticity of the marginal utility of consumption as presented in Figure 1 (c) are indeed widely dispersed, with a mean of 1.35 and a median and mode of 1 . These values provide some support to the often made assumption of logarithmic utility.

\subsubsection{Growth Rate of Real Per-Capita Consumption}

Figure 1 (d) presents the results of our respondents' forecasts of the growth rate of real per-capita consumption, $g$. The overwhelming majority forecast a positive growth rate, with a mean of 1.7 percent and a median of 1.6 percent (cf. Table 1 ). This is close to the 2 percent growth rate of consumption per-capita in the western world for the last two centuries (Gollier 2012) and the 1.6 percent growth rate in GDP per-capita over the period 1900 to 2000 in non-OECD countries (Boltho and Toniolo 1999). Three experts project a negative growth rate, and 55 respondents forecast a lower growth rate than the IPCC's (2000) lower bound projection of 1.3 percent for the period from 1990 to 2100. 28 experts forecast a growth rate larger than 2 percent.

\subsubsection{Real Risk-Free Interest Rate}

Over the period 1900-2010, the global average real risk-free rate, $r$, was approximately 1 percent for bills and 2 percent for bonds (Dimson et al. 2011). For individual countries the rates are 1.1 percent for bills and 1.9 percent for bonds for the US, 0.8 percent and 2.0 percent for the UK and -0.5 percent and -0.6 percent for Japan (Dimson et al. 2011; see also Gollier 2012 for similar figures). The average response to our survey was 2.38 percent, with a standard deviation of 1.32 percentage points and a median value of 2 percent. The maximum forecast is 6 percent, while the minimum value, forecasted by three experts, is 0 . The forecasted long-term global real risk-free interest rate according to our sample of experts is thus slightly higher than the estimated world average real risk-free rate of return on bonds over the past century. 


\subsubsection{Normative versus Positive Approaches}

A central point of disagreement on the SDR concerns the question of whether normative issues, involving justice towards future generations, or positive issues, involving forecast average future returns to financial assets, or a mix of the two should determine the SDR (Arrow et al. 1996, 2014). Not everyone agrees that discounted utilitarianism is the correct ethical basis for intergenerational decision-making in the first place. For instance, some prefer deontological ethics which emphasize duties, while others prefer rights-based approaches. In line with this history of disagreement on the SDR, our intention for Question 5 is to establish the extent to which recommendations on the SDR are influenced by "positive predictions and ethical judgments" (Ricketts and Shoesmith 1992: 210-211). A clear finding from our data is that a large majority of experts ( 80 percent) think that both dimensions are relevant (see Figure 1 (f)). However, they generally recommend that governmental institutions should place greater weight on normative issues in determining the SDR; this has a mean (median) weighting of 61.53 percent (70 percent). When considering extreme weights, 14 percent ( 5 percent) of experts placed 0 (100 percent) weight on positive considerations, while 42 experts were divided equally between the two rationales; making this the modal response. These findings emphasize that setting the SDR requires both forecasts and value judgments.

\subsection{Qualitative Responses}

More than half of our respondents provided comments ranging from short remarks, such as "risk matters", to explanations over multiple pages. The qualitative observations provide a rich body of evidence which shed light on various complexities of the theory and practice of social discounting. We group these individual comments into four main categories that address (i) individual survey questions Q1Q5, (ii) technical issues, (iii) methodological issues, and (iv) concerns about limited expertise. Each category has multiple subcategories.

Table 2 provides an overview of the most common issues raised, including the number of experts that commented upon the respective issue and an example quote, sometimes edited for brevity. The five most often raised are: 'declining discount rates and time-horizon', 'uncertainty', 'substitutability and environmental scarcity', 'heterogeneity and aggregation', and 'comparison to the Ramsey Rule'. 
Table 2: Overview of Qualitative Responses

\begin{tabular}{|c|c|c|}
\hline Issue & $\mathbf{N}$ & Exemplary quote \\
\hline Q1: Growth rate & 14 & $\begin{array}{l}\text { I foresee a very bright economic future with a continued } 2 \\
\text { percent growth rate for the coming century. }\end{array}$ \\
\hline Q2: Pure time preference & 10 & I see no reason to treat generations not equally. \\
\hline $\begin{array}{l}\text { Q3: Elasticity of } \\
\text { marginal utility }\end{array}$ & 12 & $\begin{array}{l}\text { The elasticity of marginal utility of consumption is heteroge- } \\
\text { neous, and using a single value is a crude simplification. }\end{array}$ \\
\hline $\begin{array}{l}\text { Q4: Real risk-free interest } \\
\text { rate }\end{array}$ & 8 & $\begin{array}{l}\text { There is no interest rate for } 100 \text { year horizon (to my knowl- } \\
\text { edge). }\end{array}$ \\
\hline Q5: Normative vs. positive & 16 & $\begin{array}{l}\text { The components of the SDR are overwhelmingly normative } \\
\text { in nature. }\end{array}$ \\
\hline $\begin{array}{l}\text { Declining discount rates } \\
\text { and time horizon }\end{array}$ & 20 & $\begin{array}{l}\text { I am more comfortable with declining discount rates }[\ldots] \text { due } \\
\text { both to declining time preference rates and to uncertainty } \\
\text { about future consumption growth. }\end{array}$ \\
\hline $\begin{array}{l}\text { Heterogeneity and aggre- } \\
\text { gation }\end{array}$ & 19 & $\begin{array}{l}\text { Ideally, the input for our [social welfare function] would be a } \\
\text { utility function that allows for heterogeneous preferences. }\end{array}$ \\
\hline Opportunity cost of funds & 8 & $\begin{array}{l}\text { SDRs should reflect the social opportunity cost of borrowed } \\
\text { funds. }\end{array}$ \\
\hline Project risk & 6 & $\begin{array}{l}\text { We would have to consider very carefully the risk structure } \\
\text { of the investment to get a correct discount rate. }\end{array}$ \\
\hline $\begin{array}{l}\text { Relative prices of } \\
\text { non-marketed goods }\end{array}$ & 20 & $\begin{array}{l}\text { If future costs/benefits accrue e.g. to environmental ameni- } \\
\text { ties, I would argue for a very low discount rate, based on an } \\
\text { expectation of increasing relative prices for these goods. }\end{array}$ \\
\hline Uncertainty & 20 & $\begin{array}{l}\text { We need to admit that the current state of the world is full } \\
\text { of uncertainties. [Yet] most uncertainties are neglected, and } \\
\text { sometimes few remain when these are considered most im- } \\
\text { portant, [...] or easiest to accommodate. }\end{array}$ \\
\hline Alternatives to discounting & 15 & $\begin{array}{l}\text { Instead of imposing a [social welfare function] and calculate } \\
\text { the corresponding optimum, it is 'better' to depict a set of fea- } \\
\text { sible paths of consumption, production, temperature, income } \\
\text { distribution, etc. and let the policy maker make a choice. }\end{array}$ \\
\hline Comments on the survey & 14 & $\begin{array}{l}\text { The search for THE discount rate, if that is your project, is } \\
\text { deeply flawed. }\end{array}$ \\
\hline Confidence intervals & 8 & I would also insist on providing confidence intervals. \\
\hline Ramsey Rule & 17 & $\begin{array}{l}\text { My discount rate is less than implied by the Ramsey rule } \\
\text { because I use the extended rule, incorporating uncertainty. }\end{array}$ \\
\hline Role of experts & 7 & $\begin{array}{l}\text { I really think economists have very little special expertise } \\
\text { in knowing the 'right' number. These parameters should be } \\
\text { chosen in an open, iterative way with an eye toward under- } \\
\text { standing the consequences of different choices. }\end{array}$ \\
\hline Limited confidence & 13 & $\begin{array}{l}\text { Please ignore my response to Q4: I don't have the knowledge } \\
\text { to make a meaningful forecast. }\end{array}$ \\
\hline Limited expertise & 5 & I am not a real expert on these issues. \\
\hline
\end{tabular}




\subsection{Non-Response Bias and Representativeness}

We followed several standard procedures to test for the existence of non-response bias. First, from December 2014 to April 2015 we contacted via e-mail and telephone 60 randomly selected non-respondents. This allowed us to obtain a further 38 responses, with 14 of these experts providing qualitative data and 24 giving reasons for their initial non-responses. ${ }^{6}$

Second, our sample includes quantitative responses from 11 of the 13 "blue ribbon" experts on social discounting from the Arrow et al. (2012) panel that advised the US EPA. ${ }^{7}$

Third, we divide the sample between early and late responses (Dalecki et al. 1993, Necker 2014), defined by the subsample of 58 experts that directly responded to the first e-mail and those that answered a reminder e-mail. Potential non-response bias is checked for by comparison of the mean and median responses of each of these groups, which are reported in Table 3. While there are differences regarding some of the discounting determinants, we find that there are no statistically significant differences in the mean and median SDR values between different groups.

A further common measure for potential non-response bias is to consider groups by gender and location (Necker 2014). ${ }^{8}$ We find that male experts selected into responding to our survey relative to the non-response group (91 percent versus 81 percent). The proportions of respondents and non-respondents are balanced in terms of characteristics such as being a full Professor (49 percent versus 48 percent) and average year of Ph.D. completion (1993.6 versus 1993.7). Experts currently based in Europe selected into responding (49 percent of respondents versus 32 percent of nonrespondent), which provides some indicative evidence for a potential geographical

\footnotetext{
${ }^{6}$ Reasons include having insufficient time (11 times) or expertise (10 times). The high proportion of respondents stating to be no expert suggests self-selection of true experts into responding to the initial survey.

${ }^{7} \mathrm{~A}$ twelfth panel member initially provided qualitative evidence only, but stated after the survey was completed that he would "follow the view of the median panelist."

${ }^{8}$ Personal data are obtained, where possible, from the experts' own web pages. We collect information on current continental location, gender, whether of not they have a professorial title, and year of Ph.D. graduation as a proxy for (academic) age. We are able to identify 89 respondents from Europe, 80 from the Americas and 16 from the Rest of the World (RoW), who work exclusively from Asia and Oceania. We have 167 male respondents, while only 16 women gave quantitative answers to our questionnaire. Approximately half our sample are professors and the mean year of Ph.D. graduation is 1994 .
} 
Table 3: Comparison with Non-Respondents and Arrow et al. (2012) Experts

\begin{tabular}{|c|c|c|c|c|c|c|c|c|}
\hline & g & $\delta$ & $\eta$ & $\mathbf{r}$ & Normative & SDR & SDRmin & SDRmax \\
\hline & \multicolumn{8}{|c|}{ Results from the 185 quantitative responses } \\
\hline Mean & 1.70 & 1.10 & 1.35 & 2.38 & 61.53 & 2.27 & 1.12 & 4.14 \\
\hline Median & 1.60 & 0.50 & 1.00 & 2.00 & 70.00 & 2.00 & 1.00 & 3.50 \\
\hline \multirow[t]{2}{*}{$\mathrm{N}$} & 181 & 180 & 173 & 176 & 182 & 181 & 182 & 183 \\
\hline & \multicolumn{8}{|c|}{ Results from the 14 randomly selected previous non-respondent responses } \\
\hline Mean & 1.63 & 1.46 & 1.23 & 1.96 & 71.36 & 2.02 & 1.01 & 3.09 \\
\hline Median & 1.50 & 1.00 & 1.00 & 1.75 & 75.00 & 2.00 & 0.63 & 3.00 \\
\hline \multirow[t]{2}{*}{$\mathrm{N}$} & 12 & 12 & 8 & 12 & 12 & 13 & 14 & 13 \\
\hline & \multicolumn{8}{|c|}{ Results from 11 of the 13 Arrow et al. (2012) panel experts } \\
\hline Mean & 1.80 & 0.60 & 1.51 & 2.66 & 57.27 & 2.62 & 1.30 & 4.00 \\
\hline Median & 2.00 & 0.50 & 1.50 & 3.00 & 50.00 & 3.00 & 1.00 & 4.00 \\
\hline \multirow[t]{2}{*}{$\mathrm{N}$} & 11 & 11 & 11 & 11 & 11 & 11 & 11 & 11 \\
\hline & \multicolumn{8}{|c|}{ Results from the 58 early responses } \\
\hline Mean & 1.49 & 0.73 & 1.47 & 2.26 & 60.14 & 1.99 & 0.92 & 3.68 \\
\hline Median & 1.50 & 0.38 & 1.50 & 2.00 & 50.00 & 2.00 & 0.75 & 3.00 \\
\hline \multirow[t]{2}{*}{$\mathrm{N}$} & 58 & 58 & 56 & 58 & 58 & 58 & 58 & 58 \\
\hline & \multicolumn{8}{|c|}{ Results from the 127 late responses } \\
\hline Mean & 1.80 & 1.27 & 1.29 & 2.44 & 62.18 & 2.40 & 1.21 & 4.35 \\
\hline Median & 1.80 & 0.90 & 1.00 & 2.00 & 70.00 & 2.00 & 1.00 & 4.00 \\
\hline $\mathrm{N}$ & 123 & 122 & 117 & 118 & 124 & 123 & 124 & 125 \\
\hline
\end{tabular}

bias. This may have led to a slight underestimation of the mean SDR given the propensity of Europeans to be more normative than non-Europeans, as discussed in Section 4.1.1.

We present a more detailed analysis of non-response bias checks in Supplementary material C. Overall, our findings do not suggest substantial and systematic unidirectional non-response biases for SDR recommendations. 


\section{Analysis}

\subsection{The Determinants of Expert Responses}

We now examine factors which can be used to explain each expert's recommended SDR. In addition to the quantitative and qualitative answers provided in the survey, we also consider expert's personal characteristics.

\subsubsection{Associations between the SDR and its Determinants}

We start by considering pairwise correlation coefficients between different quantitative variables and personal characteristics. Consistent with the Ramsey Rule, the recommended SDR is positively associated with $\delta, g$, and the imputed SRTP. ${ }^{9}$ However, in absolute terms, the correlation with the SRTP is surprisingly low at 35 percent, and lower than the 42 percent correlation between the SDR and the risk-free interest rate response. There is a -43 percent correlation between the SDR and the weight placed on normative considerations, strongly suggesting that those who place more emphasis on market-based rates of return recommend higher SDRs. A number of other interesting features emerge. Consistent with the strict optimality Ramsey Rule, the risk-free interest rate is highly positively correlated with forecasts of future growth and, to a slightly lesser extent, the rate of pure time preference. The correlation between the SRTP and both the risk-free interest rate and the SDR is very similar at just over 30 percent. Those who place greater weight on normative considerations are associated with lower rates of pure time preference. These normatively inclined experts are also more likely to be pessimistic about our economic future and forecast lower future interest rates.

In terms of the relationship between the recommended SDR and the personal characteristics of the respondent, there are clear negative correlations between SDR recommendations and experts who are currently located in Europe as well as expert's academic age as proxied by year of Ph.D. completion. ${ }^{10}$

\footnotetext{
${ }^{9}$ The correlation between the SDR and $\eta$ is small and statistically insignificant.

${ }^{10}$ The 88 experts currently located in Europe had a mean (median) SDR recommendation of 1.91 percent ( 2 percent), compared to 2.56 percent ( 2 percent) for the 77 currently based in the Americas and 2.79 percent (2.5 percent) for the 14 in Asia and Oceania. The 50 experts we identified with a Ph.D. completion date after 2001 had a mean (median) SDR recommendation of 1.84 percent (1.75 percent), compared with 2.29 percent (2.05 percent) for the 45 experts who graduated between 1991 and 2001 and 2.23 percent (2 percent) for the 43 finishing their Ph.D. before 1991. This
} 
Table 4: Correlations among Responses and Expert's Characteristics

\begin{tabular}{|c|c|c|c|c|c|c|c|c|c|c|}
\hline & $g$ & $\delta$ & $\eta$ & SRTP & $r$ & Normative & SDR & European & RoW & Prof \\
\hline$\delta$ & $36 \%$ & & & & & & & & & \\
\hline \multicolumn{11}{|l|}{$\eta$} \\
\hline SRTP & $69 \%$ & $59 \%$ & $57 \%$ & & & & & & & \\
\hline$r$ & $40 \%$ & $21 \%$ & & $31 \%$ & & & & & & \\
\hline Normative & $-20 \%$ & $-21 \%$ & & $-16 \%$ & $-17 \%$ & & & & & \\
\hline SDR & $40 \%$ & $31 \%$ & & $35 \%$ & $42 \%$ & $-43 \%$ & & & & \\
\hline Europe & & $-16 \%$ & & $-17 \%$ & & $20 \%$ & $-21 \%$ & & & \\
\hline ROW & & & $31 \%$ & $30 \%$ & & & & $-28 \%$ & & \\
\hline Prof & & & $20 \%$ & & & & & & & \\
\hline Ph.D. Year & & & $-23 \%$ & & & & $-18 \%$ & & & $-37 \%$ \\
\hline
\end{tabular}

For values that are statistically significant at the 5 percent two-sided level, this table provides pairwise correlation coefficients for a number of variables of interest. These include the components of the SRTP, the risk-free interest rate, the weight placed on normative arguments, the recommended SDR, and respondents' personal characteristics. The last category includes unitary dummy variables if the expert is currently based either in Europe or the Rest of the World (RoW), and if they hold a professorial position.

\subsubsection{Qualitative Responses and Discounting Determinants}

Overall, experts who provided qualitative comments recommended an average SDR that was 0.42 percentage points lower than those who only gave quantitative answers. They also responded with a lower pure rate of time preference $(-0.52)$, forecast a lower per-capita growth rate (-0.54) and risk-free interest rate (-0.43), and their average imputed SRTP is lower as a consequence (-1.31). These differences are all significant at the 10 percent level.

When qualitative comments are categorized into the four most frequent issues raised, we obtain a clearer picture of the association between these concerns and the recommended SDR. ${ }^{11}$ The results, discussed in more detail in Supplementary material D, suggest that the negative relationship between qualitative and quantitative responses is driven mainly by those who mention declining discount rates and uncertainty and those who are concerned about relative price effects of nonmarketed environmental goods. That experts commenting upon declining discount rates (DDR) recommend lower SDRs for the long-term is consistent with arguments provided in the literature (Arrow et al. 2013; Cropper et al. 2014). Furthermore,

is consistent with the increased influence of declining discount rates in the academic literature in recent years, and the prominence given to the low discount rate in the Stern Review.

${ }^{11}$ As comments on the fifth most-mentioned category 'comparison to the Ramsey Rule' are not significantly associated with different forecasts and recommendations in univariate regressions (at the 10 percent level) we exclude it from further analysis. 
that those who comment on uncertainty recommend lower SDRs is consistent with the view that uncertainty tends to lower the appropriate SDR (Gollier 2008; Traeger 2009; Weitzman 1998; Weitzman and Gollier 2010). For those experts commenting on relative price effects, we not only find lower recommended SDR values and rates of pure time preference, but also lower forecasted growth and interest rates. While lower SDRs and pessimism about future growth can be traced back to the literature on dual discounting and the relative price effects of non-marketed environmental goods (Gollier 2010; Sterner and Persson 2008; Traeger 2011), this seems to be coupled with a strong concern for intergenerational equity.

\subsubsection{Multivariate Analysis of Discounting Determinants}

Finally, we report the results of multivariate analysis of the determinants of the SDR to disentangle the relative importance of some of the characteristics that were analyzed on a pairwise basis above. Table 5 presents the results of a number of ordinary least squares (OLS) regressions with the recommended SDR as the dependent variable, and various potential explanatory factors.

The most robust determinant of the SDR is the 'normative weight'. This effect is negative, and statistically significant at the 1 percent level in all the models. Each additional normative percentage-point reduces the recommended SDR by approximately 0.02 percentage points, implying that a pure 'positivist' (normative scale $=0$ ) would have a SDR 2 percentage points higher than a pure 'normativist' (normative scale $=100$ percent). Although regression (1) shows a sizeable negative 'European effect', this seems to be an artifact of a European tendency to be more normative, and the fact that the European respondents were academically younger (2). While it appears that having raised comments has predictive power on recommend SDRs (3), this effect disappears once we control again for academic age (4). Further, we find that the presence of the four most frequently raised comments (see section 4.1.2) has no additional statistically significant explanatory power for the recommended SDR as long as the normative weight is accounted for (5).

With adjusted R-squared never more than 20 percent, it is clear that specifications (1) to (5) only capture some of the determinants of the SDR. It seems likely that contained within our normative-positive measure is a variety of unexplained and unobserved normative positions. Variation could also reflect differences within the positive school stemming from, for instance, differences or asymmetries in the 
Table 5: OLS Analysis of Characteristics that Determine SDR Responses

\begin{tabular}{lcccccc}
\hline & $(1)$ & $(2)$ & $(3)$ & $(4)$ & $(5)$ & $(6)$ \\
\hline Normative & $-0.023^{* * *}$ & $-0.019^{* * *}$ & $-0.023^{* * *}$ & $-0.019^{* * *}$ & $-0.018^{* * *}$ & $-0.014^{* * *}$ \\
Ph.D. year & & -0.01 & & -0.01 & -0.01 & $-0.02^{* *}$ \\
European & $-0.36^{*}$ & -0.15 & $-0.36^{*}$ & -0.16 & -0.12 & -0.04 \\
Made comment & & & $-0.41^{*}$ & -0.22 & & \\
Relative prices & & & & & -0.52 & \\
Heterogeneity & & & & & 0.18 & \\
Uncertainty & & & & -0.31 & \\
DDR & & & & & 0.05 & \\
Alternatives & & & & & & $-0.38^{*}$ \\
$r$ & & & & & & $0.29^{* * *}$ \\
$g$ & & & & & & \\
Constant & $3.82^{* * *}$ & 30.27 & $4.00^{* * *}$ & 29.42 & 30.36 & $32.76^{* *}$ \\
\hline Adjusted $\mathrm{R}^{2}$ & 0.19 & 0.17 & 0.20 & 0.17 & 0.16 & 0.37 \\
$\mathrm{~N}$ & 178 & 137 & 178 & 137 & 137 & 131 \\
\hline
\end{tabular}

Standard errors are robust; $\left.\left.{ }^{* * *}\right)^{[* * *}\right]$ refers to significance at the $10(5)[1]$ percent level.

information used to provide a global forecast. To control for these sources of variation, specification (6) includes experts' forecasts of $g$ and $r$ as well as a dummy variable to identify experts that proposed alternatives to discounted utilitarianism for intergenerational decision-making. This approximately doubles the adjusted Rsquared.

\subsection{Disagreement on Social Discount Rates}

Point recommendations on the SDR range from 0 to 10 percent. So it is perhaps unsurprising that the minimum acceptable SDRs reported by some experts are above the maximum acceptable SDRs of others (Figure 2 (a)). Yet, a closer inspection of experts' acceptable ranges shows that there is also considerable agreement on the SDR.

The colored histogram in Figure 2 (b) shows the proportion of experts whose acceptable SDR range includes any given SDR value. From this we can also conclude that, besides being the median and mode point SDR recommendation (cf. Table 1), 


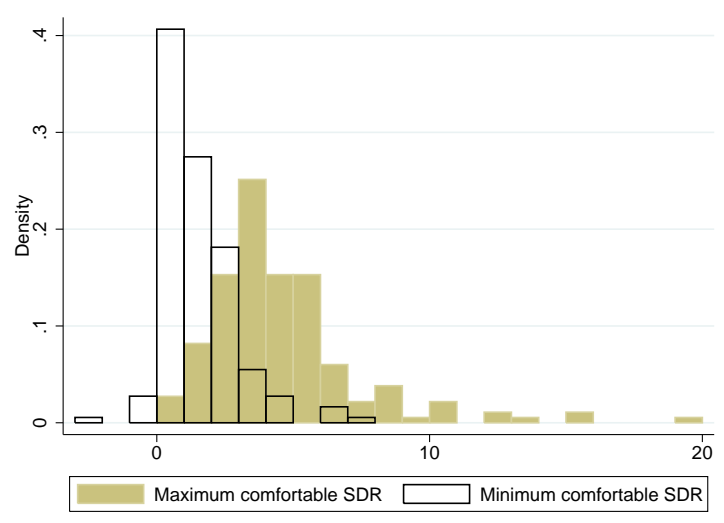

(a)

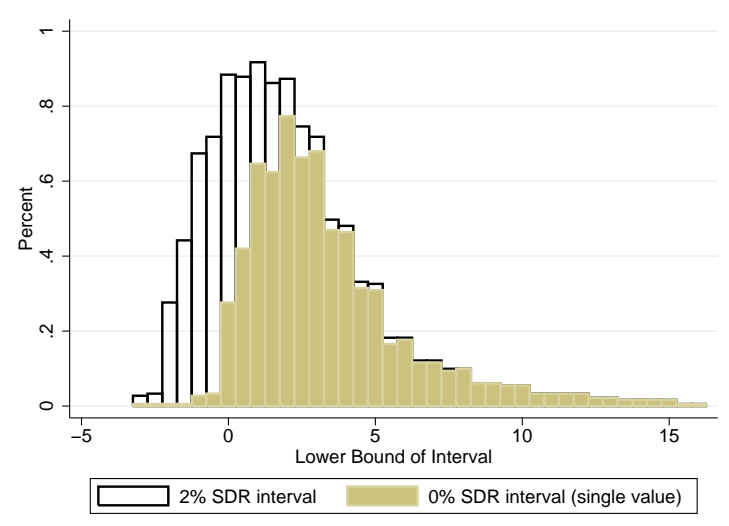

(b)

Figure 2: Figure (a) depicts the minimum and maximum SDR values that individual experts are still comfortable with recommending. The x-axis in Figure (b) shows the lower bound of an interval of given size (e.g. 2 percent) and the y-axis the proportion of experts whose acceptable SDR range has some overlap with an interval of a particular size starting at that point.

a SDR of 2 percent is also contained in the acceptable range of more experts than any other value (77 percent). The transparent histogram shows, for any given SDR value, $x$, the proportion of experts whose acceptable SDR range overlaps the interval $[x, x+2 \%]$. Looking at $x=1$ percent on this histogram reveals that the interval $[1 \%, 3 \%]$ is overlapped by the acceptable range of the SDR for 92 percent of experts.

These data on SDR ranges shed light on which of the prominent positions voiced in the academic and public debate - the long-term SDR of 4.5 percent in Nordhaus (2008), or Stern's (2007) central SDR value of 1.4 percent - is more representative of the expert community. Based on the point SDR recommendations, we find that while 30 percent of experts recommend Stern's SDR of 1.4 percent or lower, only 9 percent of experts recommend Nordhaus' value of 4.5 percent or higher, with 61 percent forming the middle ground between these two positions. The SDRs employed by Nordhaus (2008) and Stern (2007) are included in the acceptable range of 31 percent and 58 percent of experts, respectively. While there is more support for Stern's position, our findings suggest that neither may be deemed robust enough by policy-makers, who may prefer instead to take a position between the two.

\subsection{Experts' SDRs and the Ramsey Rule}

An important question for improving governmental guidance on social discount- 
ing is whether experts' SDR recommendations are determined by the Ramsey Rule. We examine all three possible representation of this as outlined in the Introduction; the strict optimality form $(r=S D R=S R T P)$, the consumption $(S D R=S R T P)$, and the production $(S D R=r)$, side approaches.

We first impute the Ramsey Rule's SRTP using responses on its individual components from each expert. The mean value is 3.48 percent and the median is 3 percent (see Table 1). The mean SRTP is thus 1.21 percentage points higher than the mean SDR. The risk-free interest rate is closer on average to the reported SDR in our sample with the mean difference between the two being only 0.11 percentage points, but this hides a great deal of heterogeneity.

Figures 3 (a) and (b) display the cross-sectional histograms of $S D R-S R T P$ and $S D R-r$, excluding five and two outliers, respectively. The SDR coincides with the SRTP (real risk-free interest rate) for only 36 (47) respondents. For 18 of these experts, less than 10 percent of the sample, the Ramsey Rule holds in its strict optimality form. Overall, the responses of only 35 percent of respondents can be reconciled with any of the representations of the Ramsey Rule. ${ }^{12}$ Analysis of the response time does not suggest that these discrepancies are due to errors made in haste. The root cause of the discrepancies between an expert's implied SRTP, or $r$, and their SDR varies from one expert to another for reasons often revealed by their qualitative responses.

SDR $<$ SRTP A typical reason for why experts reported $S D R<S R T P$ concerned uncertainty of growth. ${ }^{13}$ This concept was captured by one expert as: " $m y$ discount rate is less than implied by the Ramsey rule because I use the extended rule, incorporating uncertainty about long term growth". In this extended version of the Ramsey Rule, the precautionary savings motive results in SRTP $-S D R$ $=0.5 \eta(\eta+1) \sigma^{2}$, where $\sigma^{2}$ is the volatility of real per-capita consumption growth (Gollier 2002, 2011). While we do not elicit forecasts of $\sigma$, we can infer the value of this parameter that makes the SRTP consistent with the SDR for any given expert.

\footnotetext{
${ }^{12}$ We also examine whether experts may have used a mixed interest rate-SRTP approach weighted by their recommended positive and normative weight to determine the SDR: $S D R=w r+(1-$ $w)(\delta+\eta g)$, where $w \in[0,1]$ is the weight to be put on positive issues. We find that the SDR of only 9 experts coincides with this mixed interest rate-SRTP approach in addition to the 18 experts for whom the Ramsey Rule holds in its strict optimality form.

${ }^{13}$ Recall that the survey instrument referred to certainty-equivalent costs and benefits, but said nothing about the certainty, or otherwise, of future growth.
} 


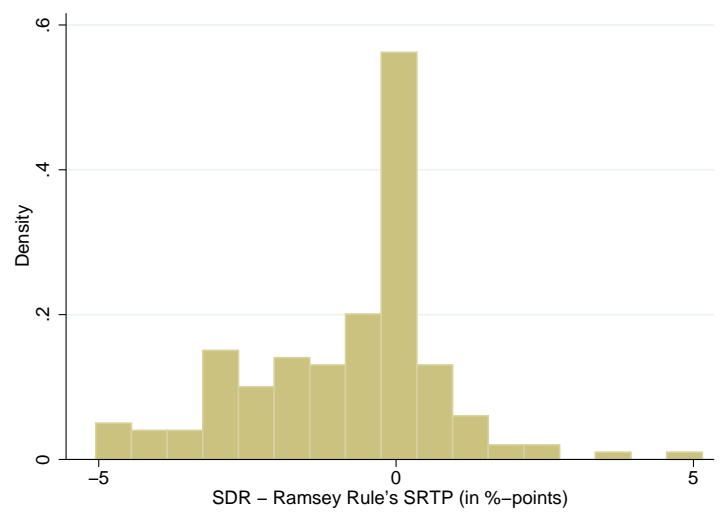

(a)

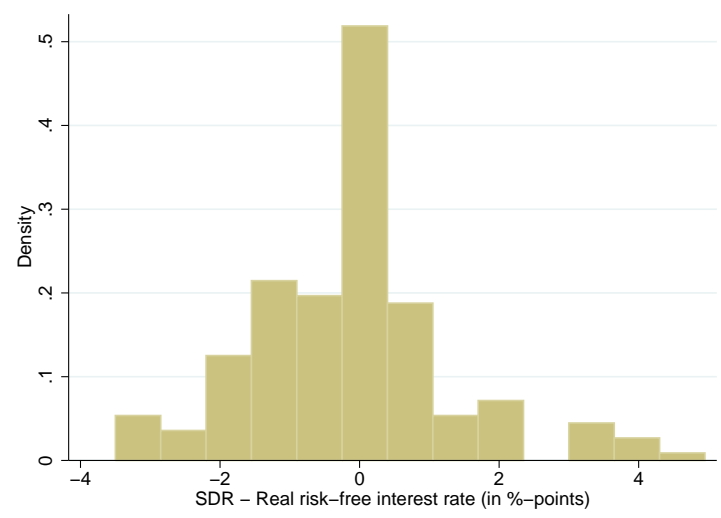

(b)

Figure 3: Histogram of the difference between the recommended SDR and (a) the imputed Ramsey Rule's SRTP, as well as (b) the real risk-free interest rate, in the interval $[-5.5,5.5]$.

We can reconcile the SDR with the SRTP of 7 respondents through the extended Ramsey Rule if their estimate of $\sigma \in(0 \%, 3.6 \%]$. This is the value of $\sigma$ used by Gollier (2012, Table 3.1) to calibrate the model. Allowing $\sigma \in(0 \%, 9 \%]$, the SDR response of 41 experts can be reconciled with their SRTP through the extended Ramsey Rule. The mean (median) value of $\sigma$ that ensures consistency between the SDR and SRTP response for the 98 experts for whom $S D R<S R T P$ is 11 percent (10 percent); this is considerably higher than standard estimates for this parameter value (Gollier 2011), implying that the precautionary savings motive was not the only driving factor for many expert responses.

Other arguments concerned relative price effects, with one expert arguing that "if the future costs/benefits accrue to non-monetary goods (e.g. environmental amenities) I would argue for a very low discount rate ..., based on an expectation of increasing relative prices for these goods (so my recommended [SDR] of 3 percent above is adjusted downwards...)". Another group of experts pointed to the use of declining discount rates to motivate their lower SDR. ${ }^{14}$

\footnotetext{
${ }^{14}$ Space does not allow a detailed discussion of each technical extension here. We refer the reader to Arrow et al. (2014), Gollier and Hammitt (2014) and Heal (2009) for overviews and the literature on Ramsey Rule extensions: uncertainty (e.g. Gollier 2002, 2008; Traeger 2009, 2013; Weitzman 1998; Weitzman and Gollier 2010), declining discount rates (e.g. Cropper et al. 2014; Gollier et al. 2008; Groom et al. 2005; Newell and Pizer 2003; Weitzman 2001) and relative price effects of environmental goods (e.g. Gollier 2010; Traeger 2011).
} 
SDR $>$ SRTP Figure 3(a) also shows that many experts recommended SDRs that are higher than their imputed SRTP. Such positions were typically motivated by opportunity cost arguments. One expert, for whom $S D R>r>S R T P$ stated "no mention is made here of the opportunity cost of government funds". Another stated: "You need one rate to weed out public projects that are dominated by the private sector and another to evaluate which of the remaining projects pass the social present value test". Both comments indicate the need to evaluate intergenerational projects using the social opportunity cost of capital, rather than the SRTP, and the idea that the former will typically be higher. Indeed, those experts for whom $S D R>S R T P$ place a substantially greater weight on positive issues for determining the SDR than those for whom $S D R<S R T P$ (50 percent positive compared to 38 percent on average).

SDR and the risk-free interest rate A few experts also highlighted the relation of their SDR recommendation to their forecasted real risk-free interest rate. For instance, one expert explicitly stated that "the real social discount rate should be the risk-free interest rate", while others remarked that "incomplete futures markets justify social discount rates lower than real market rates". Moreover, experts who commented upon the opportunity cost of funds recommended SDRs higher than the risk-free interest rate, while those commenting upon declining discount rates tended to recommend SDRs below their forecasted risk-free interest rate.

Beyond the Ramsey Rule Beyond the above technical arguments, which largely require extensions to the Ramsey Rule, further criticism focused on the need for alternative approaches to inform intergenerational decision-making. Experts recorded doubts about whether "a representative agent model with a standard Ramsey social welfare function is adequate in either descriptive or normative terms". They also point towards "richer ways of framing questions of intergenerational justice than simply tweaking the discount rate" by developing alternative criteria for intergenerational decision-making (see Asheim (2010) and Botzen and van den Bergh (2014) for overviews). Such approaches might "set limits in physical terms to the future development that must not be exceeded for reasons of intra- and intergenerational justice... Then use a discounted utilitarian approach to optimize development only within these limits". 
This analysis demonstrates two things. First, the qualitative evidence suggests that individual responses are theoretically motivated and display internal consistency. Second, within the expert community there are several distinct schools of thought on discounting intergenerational projects which are more nuanced than the standard normative-positive dichotomy. Overall, our findings highlight that many experts are sceptical about the central role of the Ramsey Rule in determining policy recommendations on long-term public projects.

\section{Discussion}

\subsection{Comparison to the Weitzman (2001) Survey}

A natural reference comparison for our results is the seminal survey of Weitzman (2001), who asked more than 2000 Ph.D.-level economists to report a single appropriate "real discount rate" or "rate of interest" with which to discount projects aimed at mitigating climate change. The key difference between the response data of Weitzman (2001) and our results is that we find a substantially lower mean (median) SDR recommendation, with 2.27 percent (2 percent) compared to 3.96 percent (3 percent). Furthermore, we find a much lower standard deviation of the SDR responses of 1.62 percent compared to the 2.94 percent of Weitzman's (2001) respondents, and the range of point recommendations on the SDR is much more condensed (0 to 10 percent compared to -3 percent to 27 percent). ${ }^{15}$ The modal recommended value for the SDR of 2 percent, however, is the same in both surveys.

We can point to at least three potential explanations for these differences. First, experts who have graduated from their Ph.D.s since Weitzman's survey was conducted generally recommend lower SDRs than those who have been in the profession for longer. Second, the literature that has influenced this new generation of academics - for example, on declining discount rates and the arguments articulated in the Stern Review - may have led more established scholars to reduce their SDR recommendations during their careers. Third, Weitzman's pool of potential respondents is a general economics audience, while we select only those scholars

\footnotetext{
${ }^{15}$ The standard deviation, minimum and maximum of the imputed SRTPs $(3.52 \%,-2 \%$ and $26 \%$ respectively) are, by contrast, similar to the values reported in Weitzman (2001).
} 
who have published directly on discounting and can be considered specialists in this sense. ${ }^{16}$

\subsection{What SDR Should a Government Use?}

In this section we provide advice on determining the appropriate SDR from the survey evidence. This involves answering two important questions. First, what role should experts play in providing the raw materials for the SDR? Second, how should uncertainty (of forecasts) and disagreement (on value judgments) be treated when calculating the appropriate SDR for long-term public policy making?

The first question has itself been a source of disagreement (Dasgupta 2008; Weitzman 2001). One typical criticism is that guidance on social discounting should be informed via more "democratic" means (Dasgupta 2008: 158). It is often claimed that economists do not command any special expertise in matters of ethics. Yet some discussants explicitly advocate an active role for "genuine specialists" to steer the process of setting SDRs (Pindyck 2015; Sunstein 2014: 550). This comes as no surprise, as the questions raised by intergenerational discounting are highly complex. Compared to members of the general population, experts will have spent considerably more time considering the intricate issues that arise. We also note that governmental guidance on social discounting is generally influenced by expert opinion, as are other areas of policy as evidenced by, for example, membership of Monetary Policy Committees. There is also a distinction to be drawn within economics between genuine specialists and general economists. Monetary Policy Committee members typically fall into the former category, as do those who have provided recent advice to international governments on social discounting. Therefore, while there are good arguments for more inclusive approaches, it is also imperative that advice is heard from genuine experts on the determinants of the long-term SDR.

Based on the heterogeneous responses to this survey, a decision-maker might rea-

\footnotetext{
${ }^{16}$ That real growth and interest rates in many countries are now below the rates that prevailed at the start of the Century is unlikely to be a core driving factor. The mean real risk-free interest rate response of 2.38 percent does not closely correspond to current real bond yields in major economies and is above the 2 percent long-term global average for bonds reported by Dimson et al. (2011). Similarly, the mean forecasted growth rate of real per-capita consumption of 1.7 percent is only slightly lower than the historical global average. Finally, if low current interest rates are driving the lower SDRs we would expect those who put the highest weight on positive issues for determining the SDR to be influenced more by current yields. Yet these experts tend to recommend higher SDRs.
} 
sonably then ask which single rate to use when discounting the certainty-equivalent cash flows from an intergenerational project. Deciding how best to adjudicate between conflicting opinions, and aggregate different forecasts, is a contentious issue to which there is no single accepted answer. A number of proposals do exist though. In relation to the pure rate of time preference, Heal and Millner (2014b) provide two possible resolutions to disagreement. The efficient solution is to use a declining term structure of pure time preference rates, but this introduces time inconsistent behavior. The alternative is to imagine a voting mechanism. Median voter arguments then recommend the median pure time preference, which is deemed democratic and avoids time inconsistency, but is inefficient. When experts disagree, choosing the representative agent is a matter of choosing one's poison: time inconsistency or inefficiency (Jackson and Yariv 2015).

An approach which relates to the SDR directly is to calculate the discount factor for each respondent, and then construct the social discount factor as a weighted average of the individual discount factors. This is the approach taken by Weitzman (2001) and leads to a declining term structure of SDRs. The difficulty with applying this approach to survey data is that it is not clear what weights to assign to each of the expert discount factors. While Weitzman (2001) gives each response equal importance, this has been a controversial choice (Freeman and Groom 2015; Heal and Millner 2014a,b; Jouini et al. 2010; Weitzman and Gollier 2010; Gollier and Zeckhauser 2005). In particular, Freeman and Groom (2015) show that the appropriate weighting depends on whether responses reflect disagreement on value judgments or uncertainty about forecasts. The theory of aggregation is very different in each case, and leads to vastly different outcomes. The current literature does not advise us on what weights to apply to each individual's discount factor in the present case, since some responses to the survey are purely positive, others are purely normative, yet the majority are a blend of the two.

Given the lack of clear theoretical guidance on how to aggregate individual expert responses, what remains is to rely on a data-driven approach. Fortunately, this points towards a rather clear recommendation: a long term SDR of 2 percent is not only the modal and median recommendation but also the SDR value that is included in the acceptable ranges of most experts (77 percent). Interestingly, this clear longrun SDR recommendation of 2 percent is lower than the equivalent recommendations of the UK, French and US governments. 


\section{Conclusion}

We have presented evidence from a survey of over 200 experts on the determinants of the long-term real social discount rate (SDR). This is, perhaps, the single most important driver of any cost-benefit analysis evaluating long-term public projects. We find that the mean (median) recommended SDR of our experts is 2.27 percent (2 percent). While there is considerable disagreement between respondents on point recommendations, which range from 0 to 10 percent, more than three-quarters of those surveyed would find a SDR of 2 percent acceptable. More than 90 percent are comfortable with a SDR somewhere in the interval of 1 percent to 3 percent.

A key innovation of our survey is that we not only elicit responses on the appropriate SDR itself, but also on individual discounting determinants: recommendations on the rate of pure time preference and the elasticity of marginal utility of consumption, as well as predictions of long-term per-capita consumption growth and the average real risk-free rate of interest.

Based on this disentangled data, we show that the simple Ramsey Rule, which is widely accepted as a "useful conceptual framework for examining intergenerational discounting issues" (Arrow et al. 2012: 3) and can be found in governmental guidelines on cost-benefit analysis across the world, cannot explain the responses of the majority of our experts. The conclusion that more complex models for social discounting are required is supported by the rich body of qualitative responses we received. Many of our respondents provided comments relating to a number of extension and alternatives to the simple Ramsey Rule approach. These include issues such as uncertainty, heterogeneity, relative prices of non-marketed goods as well as other societal evaluation approaches that policy guidance on social discounting should consider to ensure efficient and equitable decisions on long-term public projects.

Further inspection of the data on individual discounting determinants yields findings that transcend their value as potential inputs to governmental discounting

guidelines. First, we find that the modal value of the pure rate of time preference is zero, but with a mean (median) of 1.1 percent (0.5 percent), our results cannot confirm the IPCC's (2014: 229) conclusion that "a broad consensus for a zero or nearzero pure rate of time preference" exists among experts. Second, our data suggest that the IPCC should consider lower growth scenarios in future assessments. Third 
the median and mode recommended elasticity of marginal utility of consumption of 1 provides some support for the often made assumption of logarithmic utility. Lastly, we find that there exists considerable disagreement between experts on the relative importance of normative and positive approaches to discounting. Most report that the SDR should reflect both, highlighting that these previously accepted categories overly polarize more nuanced expert views. Engaging with both disagreement about values and uncertainty over forecasts is therefore an essential task for informing decision-making on long-term public projects.

Overall, our findings lead us to the conclusion that the prominence of the Ramsey Rule needs to be revisited and that current policy guidance concerning social discounting and the evaluation of long-term public projects needs to be updated. While not uncontentious, our survey points to a long-term global SDR for certaintyequivalent cash flows of 2 percent. 


\section{Appendix: Survey Text}

Imagine that you are asked for your advice by an international governmental organization that needs to determine the appropriate social discount rate for calculating the present value of risk-free cash flows of public projects with intergenerational consequences.

For its calculations, the organization needs single values for the components of the social discount rate. While this does not capture all of the important complexities of social discounting, including time horizon-dependent individual discount rates, it does reflect most existing policy guidance on the matter. Your answers will therefore help to improve the current state of decision-making for public investments.

Specifically, you are asked to provide your recommendations on the single number, global average and long-term (>100 years) values of the following determinants of the social discount rate:

1. Growth rate of real per-capita consumption [X percent per year].

2. Rate of societal pure time preference (or utility discount rate) [X percent].

3. Elasticity of the marginal utility of consumption $[\mathrm{X}]$.

4. Real risk-free interest rate [X percent per year]. Remember that this should be a global average and long-term forecast.

5. What relative weight (summing up to 100 percent) should the governmental body place on the following rationales for determining the social discount rate:

(a) Normative issues, involving justice towards future generations [X percent], and

(b) Descriptive issues, involving forecasted average future returns to financial assets [X percent]?

6. What is your recommended real social discount rate for evaluating the certaintyequivalent cash flows of a global public project with intergenerational consequences $[\mathrm{X}$ percent per year]?

7. What minimum and maximum real social discount rate would you be comfortable with recommending $[\mathrm{X}$ percent to $\mathrm{X}$ percent per year]?

8. Do you have any additional comments $[\mathrm{X}]$ ? 


\section{References}

Arrow, K.J. (1999), Discounting, Morality, and Gaming. In: Discounting and Intergenerational Equity, edited by Portney, P.R., and J.P. Weyant. Washington, D.C.: Resources for the Future.

Arrow, K.J., Cline, W., Mäler, K.G., Munasinghe, M., Squitieri, R., and J. Stiglitz (1996), Intertemporal Equity, Discounting, and Economic Efficiency. In: Climate Change: Economic and Social Dimensions of Climate Change, Contribution of Working Group III to the Second Assessment Report of the Intergovernmental Panel on Climate Change, edited by Bruce, J.P., Lee, H., and E.F. Haites. Cambridge: Cambridge University Press.

Arrow, K.J., Cropper, M.L., Gollier, C., Groom, B., Heal, G., Newell, R., Nordhaus, W.D., Pindyck, R., Pizer, W., Portney, P., Sterner, T., Tol, R.S.J., and M.L. Weitzman (2012), How Should Benefits and Costs Be Discounted in an Intergenerational Context? The Views of an Expert Panel, RFF Discussion Paper 12(53), Resources for the Future.

Arrow, K.J., Cropper, M.L., Gollier, C., Groom, B., Heal, G., Newell, R., Nordhaus, W.D., Pindyck, R., Pizer, W., Portney, P., Sterner, T., Tol, R.S.J., and M.L. Weitzman (2013), Determining Benefits and Costs for Future Generations, Science 341(6144): 349-350.

Arrow, K.J., Cropper, M.L., Gollier, C., Groom, B., Heal, G., Newell, R., Nordhaus, W.D., Pindyck, R., Pizer, W., Portney, P., Sterner, T., Tol, R.S.J., and M.L. Weitzman (2014), Should Governments Use a Declining Discount Rate in Project Analysis?, Review of Environmental Economics and Policy 8(2): 145-163.

Asheim, G.B. (2010), Intergenerational Equity, Annual Review of Economics 2(1): $197-222$.

Baumol, W.J. (1968), On the Social Rate of Discount, American Economic Review 57: 788-802.

Boltho, A., and G. Toniolo (1999), The Assessment: The Twentieth Century Achievements, Failures, Lessons, Oxford Review of Economic Policy 4: 1-17. 
Botzen, W.W., and J.C. van den Bergh (2014), Specifications of Social Welfare in Economic Studies of Climate Policy: Overview of Criteria and Related Policy Insights, Environmental and Resource Economics 58(1): 1-33.

Combes, P.P., and L. Linnemer (2010), Inferring Missing Citations: A Quantitative Multi-Criteria Ranking of all Journals in Economics, GREQAM Working Paper 2010-25.

Cowell, F.A., and K. Gardiner (1999), Welfare Weights, OFT Economic Research Paper 202, STICERD, London School of Economics.

Cropper, M.L., Freeman, M.C., Groom, B., and W. Pizer (2014), Declining Discount Rates, American Economic Review: Papers and Proceedings 104(5): 538-543.

Dalecki, M.G., Whitehead, J.C., and G.C. Blomquist (1993), Sample Non-Response Bias and Aggregate Benefits in Contingent Valuation: An Examination of Early, Late and Non-Respondents, Journal of Environmental Management 38(2): 133143.

Dasgupta, P. (2008), Discounting Climate Change, Journal of Risk and Uncertainty 37(2): 141-169.

Dimson, E., Marsh, P., and M. Staunton (2011), Equity Premia Around the World, SSRN Working Paper, available at: http://ssrn.com/abstract=1940165.

Freeman, M. C., and B. Groom (2015), Positively Gamma Discounting: Combining the Opinions of Experts on the Social Discount Rate, The Economic Journal, 125(585): 1015-1024.

Giglio, S., Maggiori, M., and J. Stroebel (2015), Very Long-Run Discount Rates, Quarterly Journal of Economics, 130(1): 1-53.

Gollier, C. (2002), Time Horizon and the Discount Rate, Journal of Economic Theory 107: 463-473.

Gollier, C. (2008), Discounting with Fat-Tailed Economic Growth, Journal of Risk and Uncertainty 37(2-3): 171-186.

Gollier, C. (2010), Ecological Discounting, Journal of Economic Theory 145: 812829. 
Gollier, C. (2011), On the Underestimation of the Precautionary Effect in Discounting, The Geneva Risk and Insurance Review 36(2): 95-111.

Gollier, C. (2012), Pricing the Future: The Economics of Discounting in an Uncertain World, Princeton: Princeton Press.

Gollier, C., and J.K. Hammitt (2014), The Long-Run Discount Rate Controversy, Annual Review of Resource Economics 6: 273-95.

Gollier, C., Koundouri, P., and T. Pantelidis (2008), Declining Discount Rates: Economic Justifications and Implications for Long-Run Policy, Economic Policy 56: $757-795$.

Gollier, C., and R. Zeckhauser (2005), Aggregation of Heterogeneous Time Preferences, Journal of Political Economy 113(4): 878-896.

Groom, B., Hepburn, C., Koundouri, P., and D. Pearce (2005), Declining Discount Rates: The Long and the Short of it, Environmental and Resource Economics 32(4): 445-493.

Heal, G. (2009), The Economics of Climate Change: A Post-Stern Perspective, Climatic Change 96: 275-297.

Heal, G., and A. Millner (2014a), Agreeing to Disagree on Climate Policy, Proceedings of the National Academy of Sciences 111(10): 3695-3698.

Heal, G., and A. Millner (2014b), Resolving Intertemporal Conflicts: Economics vs Politics, NBER Working Paper 20705.

[HMT 2003] Her Majesty's Treasury (2003), The Green Book: Appraisal and Evaluation in Central Government, London: UK Treasury.

[IPCC 2000] Intergovernmental Panel on Climate Change (2000), The IPCC Special Report on Emissions Scenarios (SRES), Geneva: IPCC.

[IPCC 2014] Kolstad, C. et al. (2014), Social, Economic and Ethical Concepts and Methods. In: Mitigation of Climate Change. Contribution of Working Group III to the Fifth Assessment Report of the Intergovernmental Panel on Climate Change, edited by Edenhofer, O. et al. Cambridge and New York: Cambridge University Press. 
Jackson, M.O., and L. Yariv (2015), Collective Dynamic Choice: The Necessity of Time Inconsistency, Forthcoming in: American Economic Journal: Microeconomics.

Jouini, E., Marin, J.M., and C. Napp (2010), Discounting and Divergence of Opinion, Journal of Economic Theory 145: 830-59.

Koopmans, T.C. (1960), Stationary Ordinal Utility and Impatience, Econometrica 28(2): 287-309.

Lebegue, D. (2005), Revision du Taux d'Actualisation des Investissements Publics, available at: http://catalogue.polytechnique.fr/site.php?id=324\&fileid=2389.

Necker, S. (2014), Scientific Misbehavior in Economics, Research Policy 43: 17471759.

Newell, R., and W. Pizer (2003), Discounting the Distant Future: How Much Do Uncertain Rates Increase Valuations?, Journal of Environmental Economics and Management 46(1): 52-71.

Nordhaus, W.D. (2007), The Stern Review on the Economics of Climate Change, Journal of Economic Literature 45(3): 686-702.

Nordhaus, W.D. (2008), A Question of Balance: Economic Modeling of Global Warming, Yale University Press, New Haven, USA.

Pindyck, R.S. (2015), The Use and Misuse of Models for Climate Policy, NBER Working Paper No. 21097.

Ramsey, F.P. (1928), A Mathematical Theory of Saving, The Economic Journal 38(152): 543-559.

Ricketts, M., and E. Shoesmith (1992), British Economic Opinion: Positive Science or Normative Judgment?, American Economic Review: Papers and Proceedings 82(2): 210-215.

Stern, N. (2007), The Economics of Climate Change: The Stern Review, Cambridge and New York: Cambridge University Press. 
Sterner, T., and M. Persson (2008), An Even Sterner Review: Introducing Relative Prices into the Discounting Debate, Review of Environmental Economics and Policy 2(1): 61-76.

Sunstein, C.R. (2014), On Not Revisiting Official Discount Rates: Institutional Inertia and the Social Cost of Carbon, American Economic Review: Papers and Proceedings 104(5): 547-551.

Traeger, C.P. (2009), Recent Developments in the Intertemporal Modeling of Uncertainty, Annual Review of Resource Economics 1: 261-285.

Traeger, C.P. (2011), Sustainability, Limited substitutability, and Non-Constant Social Discount Rates, Journal of Environmental Economics and Management $62(2): 215-228$.

Traeger, C.P. (2013), Discounting Under Uncertainty: Disentangling the Weitzman and the Gollier Effect, Journal of Environmental Economics and Management $66(3): 573-582$.

[US EPA 2010] United States Environmental Protection Agency (2010), Guidelines for Preparing Economic Analyses, Washington D.C.: EPA 240-R-10-001

Weitzman, M.L. (1998), Why the Far-Distant Future Should Be Discounted at Its Lowest Possible Rate, Journal of Environmental Economics and Management 36(3): 201-208.

Weitzman, M.L. (2001), Gamma Discounting, American Economic Review 91(1): 260-271.

Weitzman, M.L. (2007), A Review of The Stern Review on the Economics of Climate Change, Journal of Economic Literature 45: 703-724.

Weitzman, M.L., and C. Gollier (2010), How Should the Distant Future be Discounted When Discount Rates are Uncertain?, Economic Letters 107(3): 350-353. 


\section{Supplementary Material}

\section{A Further Detail on the Selection of Experts}

Based on full-text analysis in the Google scholar engine, we searched the 102 leading economics journals (according to the ranking of Combes and Linnenmer 2010) plus the Review of Environmental Economics and Policy for publications since the year 2000 including the terms 'social discounting', 'social discount rate' or 'social discount factor' (in March/April 2014). As a result, we identified 778 potential experts. As not all pertinent contributions to the field use the term 'social discount rate', but often 'real discount rate' or simply 'discount rate', we further performed an EconLit search for the term 'discount rate' (in April 2014). To avoid picking up a large number of papers that only mention a 'discount rate' in passing somewhere in the paper, we limited the scope to a within-abstract search. This search yielded an additional 241 potential experts. We thus identified a total of 1019 unique potential experts. We then manually discarded - using a weak relevancy test - publications that are clearly not of direct relevance for our study. The criteria used to judge whether a publication is not relevant are listed below:

- If the search phrases do not appear in the article itself, but only in the reference list.

- If the publication is a book review or another non-original contribution.

- If a value for the SDR is simply applied in an analysis without reference to the literature.

- If one of the phrases is mentioned but not elaborated on.

- If the publication relies on a discount rate that is clearly not relevant to longterm social discounting by governmental bodies, such as discounting of profits or university fees.

A publication is labeled irrelevant if it meets at least one of the listed criteria. If at least one of the publications of a scholar is regarded to be relevant (i.e. passes this weak relevancy test), he or she is considered to be an expert. As a result of the above relevancy test, we exclude 365 scholars from the pool of potential experts, thus being left with 654 potential experts. For 27 of these scholars we could not obtain an e-mail address because, for example, they have left academia or are deceased. Our final population of potential experts thus contains 627 experts. $^{1}$

\footnotetext{
${ }^{1}$ Although potential experts have published in leading economics journals, a small number of them do not have a Ph.D. in economics but come from diverse fields, including law and the natural sciences.
} 


\section{B E-mail Text}

This Appendix provides the text of the initial e-mail introducing experts to the online survey.

Dear [Personal identifier],

We are targeting a select group of academics with expertise in social discounting. The objective is to elicit recommendations on fundamental issues of discounting to inform long-term public investment decision-making.

We would be most grateful if you could find the time to complete the very short survey appended below.

https://www.surveymonkey.com/s/discounting-survey

Your individual response will be held in the strictest confidence.

Many thanks for your time and cooperation,

Ben Groom (LSE), Moritz Drupp (Kiel, LSE),

Frikk Nesje (Oslo, LSE), Mark Freeman (Loughborough) 


\section{Further Checks of Non-Response Bias}

We carried out a series of robustness checks to test for potential non-response bias (see Johnson and Wislar (2012) and Necker (2014) for discussions of different testing strategies).

In the main body of the paper, we first compare our 185 quantitative responses with a random sample of 60 potential experts who had not replied by November 2014 . Second, we compare our 185 quantitative responses with the sub-sample responses of the Resources for the Future (RFF) Arrow et al. (2012) panel on intergenerational decision-making. Third, we consider differences in observable characteristics - academic age, location and gender - among respondents and non-respondents. A related check is to test for selection of environmental economists into responding. ${ }^{2}$ Indeed, we observe that environmental economists self-select into responding: $48 \%$ of respondents are environmental economists, while only $33 \%$ of the non-respondents are environmental economists. Yet, we find that environmental economists do not recommend significantly (at the at the 10 percent level) different mean and median SDRs to non-environmental economists.

Lastly, we consider differences between experts who responded to the initial wave, and those who responded to a reminder. In Table 3 we report the results of a comparison of these early and late respondents to obtain a further indirect measure of potentially biasing participation. At the 10 percent level of significance only the mean forecasted per-capita growth rate and recommended social rate of pure time preference are different between the samples of early and late respondents. The mean forecasted per-capita growth rate and recommended social rate of pure time preference are higher for the sub-sample of respondents that required a reminder. On the other hand, the median recommendation on the elasticity of marginal utility is the only median response significantly different between the subsamples, with the median of those responding immediately being higher. As a robustness check, we also divided early and late respondents into equal sized groups and found that the results were similar. The results of this additional exercise are reported in Table

\footnotetext{
${ }^{2}$ We regard an expert to be an environmental economist if the publication that led us to select her or him as a potential expert is in either American Journal of Agricultural Economics, Ecological Economics, Energy Journal, Environmental and Resource Economics, Journal of Environmental Economics and Management, Land Economics, Resource and Energy Economics, or Review of Environmental Economics and Policy.
} 
Table C.1: Alternative Comparison of Early and Late Responses

\begin{tabular}{|c|c|c|c|c|c|c|c|c|}
\hline & $g$ & $\delta$ & $\eta$ & $r$ & Normative & SDR & SDRmin & SDRmax \\
\hline \multicolumn{9}{|c|}{ Split by time of response in SurveyMonkey } \\
\hline \multicolumn{9}{|c|}{ Results from the 88 early responses } \\
\hline Mean & 1.63 & 0.93 & 1.44 & 2.42 & 61.72 & 2.18 & 1.07 & 3.89 \\
\hline Median & 1.50 & 0.50 & 1.25 & 2.00 & 70.00 & 2.00 & 1.00 & 3.25 \\
\hline $\mathrm{N}$ & 88 & 88 & 85 & 88 & 88 & 87 & 88 & 88 \\
\hline \multicolumn{9}{|c|}{ Results from the 88 late responses } \\
\hline Mean & 1.81 & 1.26 & 1.27 & 2.38 & 61.00 & 2.34 & 1.17 & 4.38 \\
\hline Median & 2.00 & 1.00 & 1.00 & 2.00 & 68.50 & 2.00 & 1.00 & 3.50 \\
\hline $\mathrm{N}$ & 85 & 85 & 83 & 81 & 88 & 87 & 87 & 87 \\
\hline
\end{tabular}

C.1. While we find some effect for those requiring a reminder versus those that responded right away, we do not find significant differences in mean and median recommendations and forecasts when we split the whole sample into equal halves and consider early and late respondents based on this definition. 


\section{Further Analysis of Qualitative Responses}

As reported in the main paper, about half of our respondents provided qualitative responses alongside their quantitative responses. Here, we analyse how raising different issues is related to the quantitative responses received. Difference in means statistically significant at the 10 percent level between those who commented and those that did not are reported in Table D.1.

We find that experts who have provided comments responded with a lower pure rate of time preference, forecast a lower per-capita growth rate and risk-free interest rate, and recommended a lower SDR and minimum value of the SDR. As is further illustrated in Table D.1, the implied SRTP is lower as a consequence. These results are qualitatively similar if the subsample of experts raising issues of limited expertise is excluded from the analysis. ${ }^{3}$

When qualitative comments are categorised into the five most frequent issues raised, we obtain a clearer picture of the association between these concerns and the quantitative responses. ${ }^{4}$ Experts raising the issue of 'DDRs and time-horizon' forecast a lower growth rate per-capita, recommended a more normative foundation for the SDR and a lower point value of the SDR, and would be comfortable with a lower minimum value of the SDR. Experts that raised the importance of 'uncertainty' tend to recommend lower values of the minimum acceptable value of the SDR and the SDR itself. Experts raising the issue of 'substitutability and environmental scarcity' recommended lower rates of pure time preference and forecast lower percapita growth rates and risk-free interest rates. These experts also recommended that normative considerations should receive more weight, while recommending a lower SDR and lower minimum and maximum values of the SDR. Their implied SRTP is also lower. Finally, experts commenting on the importance of 'heterogeneity and aggregation' recommended a lower rate of pure time preference and that the SDR should have a more normative foundation. ${ }^{5}$

\footnotetext{
${ }^{3}$ Although not shown in Table D.1 only the forecast per-capita growth rate differs statistically significantly between the subsample of experts stating limited expertise and the subsample of experts that did not raise this issue.

${ }^{4}$ Raising a comment on the 'Ramsey Rule' is not significantly associated with different forecasts and recommendations (at the 10 percent level); it is excluded from Table D.1.

${ }^{5}$ In light of the variety of heterogeneities mentioned by experts, there is no straightforward expectation on how heterogeneities impact SDR recommendations. While some respondents simply
} 


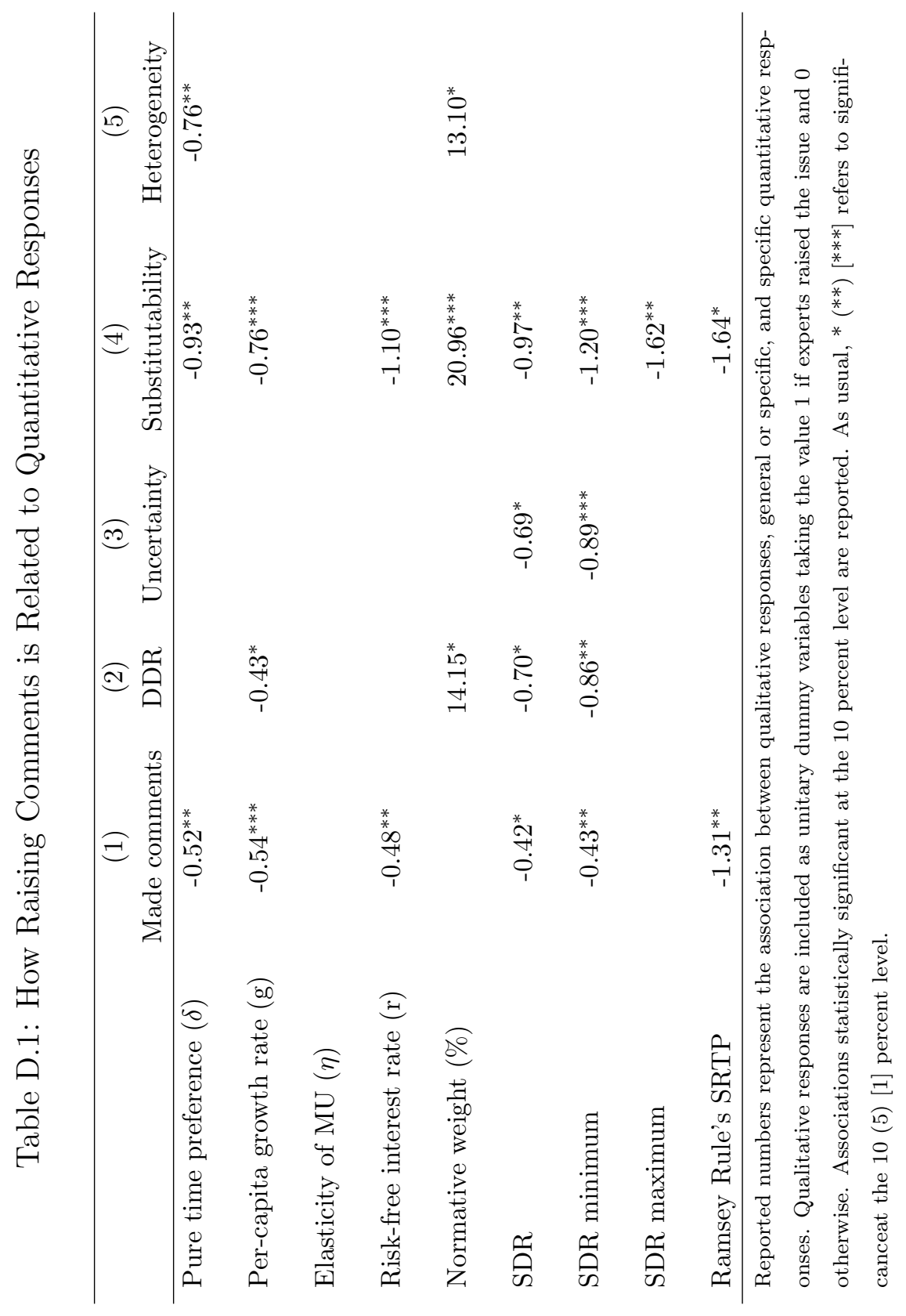


Taken as a whole, these results suggest a negative relationship between qualitative and quantitative responses. This is driven mainly by those who mention declining discount rates and uncertainty and those who are concerned about sustainability and environmental scarcity.

\section{References}

Arrow, K.J., Cropper, M.L., Gollier, C., Groom, B., Heal, G., Newell, R., Nordhaus, W.D., Pindyck, R., Pizer, W., Portney, P., Sterner, T., Tol, R.S.J., and M.L. Weitzman (2012), How Should Benefits and Costs Be Discounted in an Intergenerational Context? The Views of an Expert Panel, RFF Discussion Paper 12(53), Resources for the Future.

Combes, P.P., and L. Linnemer (2010), Inferring Missing Citations: A Quantitative Multi-Criteria Ranking of all Journals in Economics, GREQAM Working Paper 2010-25.

Johnson, T.P. and J.S. Wislar (2012), Response Rates and Nonresponse Errors in Surveys, The Journal of the American Medical Association 307(17): 1805-1806.

Necker, S. (2014), Scientific Misbehavior in Economics, Research Policy 43: 17471759 .

state that one must take the distributional effect for those "affected by the project" into account, other respondents are more specific in stating that "the discount rate should be negative if rich people pay today for poor people in the future". 